\title{
LATE GLACIAL AND HOLOCENE EVOLUTION OF LANDSCAPESON THE TERRITORY OF SPOROVSKY RESERVE (BELARUSIAN POLESIE)
}

DOI: https://doi.org/10.18509/AGB.2021.13

UDC: $51.7 / .8: 902.2(476)$

\author{
Dmitry Tsvirko', Mikola Kryvaltsevich ${ }^{2}$, Aleh Tkachou' ${ }^{2}$, \\ Yury Trifonov ${ }^{3}$, Tomasz Kalicki ${ }^{4}$, Marcin Frączek ${ }^{4}$, Piotr Kusztal ${ }^{4}$
}

\author{
${ }^{1}$ The National Academy of Sciences of Belarus, Institute for Nature Management, Belarus \\ ${ }^{2}$ The National Academy of Sciences of Belarus, Institute of History, Belarus \\ ${ }^{3}$ Belarusian State University, Faculty of Geography and Geoinformatics, Belarus \\ ${ }^{4}$ Jan Kochanowski University in Kielce, Institute of Geography and Environmental Sciences, Poland
}

corresponding author: mfraczek@ujk.edu.pl

submitted: 09.05 .2020

accepted: 29.07.2020

published: $25 \cdot 10.2020$

\begin{abstract}
Based on the results of palynological, sedimentological, radiocarbon and OSL studies, the changes that occurred during the Late Glacial and Holocene with landscapes of the territory of the Sporovsky Reserve were defined. Using archaeological research methods, it was found that the active use of the region's landscapes by human has taken place since the Neolithic.
\end{abstract}

Keywords: palaeogeography, archaeological site, river valley, lake sediments, sandy hill, remote sensing.

\section{INTRODUCTION}

The preliminary results of geoarchaeological and paleogeographic studies on the territory of the Sporovsky Biological Reserve are presented.
Research reserve is located on the territory of Belarusian Polesie in Brest region, beyond the border of the last glaciation (Fig. 1).

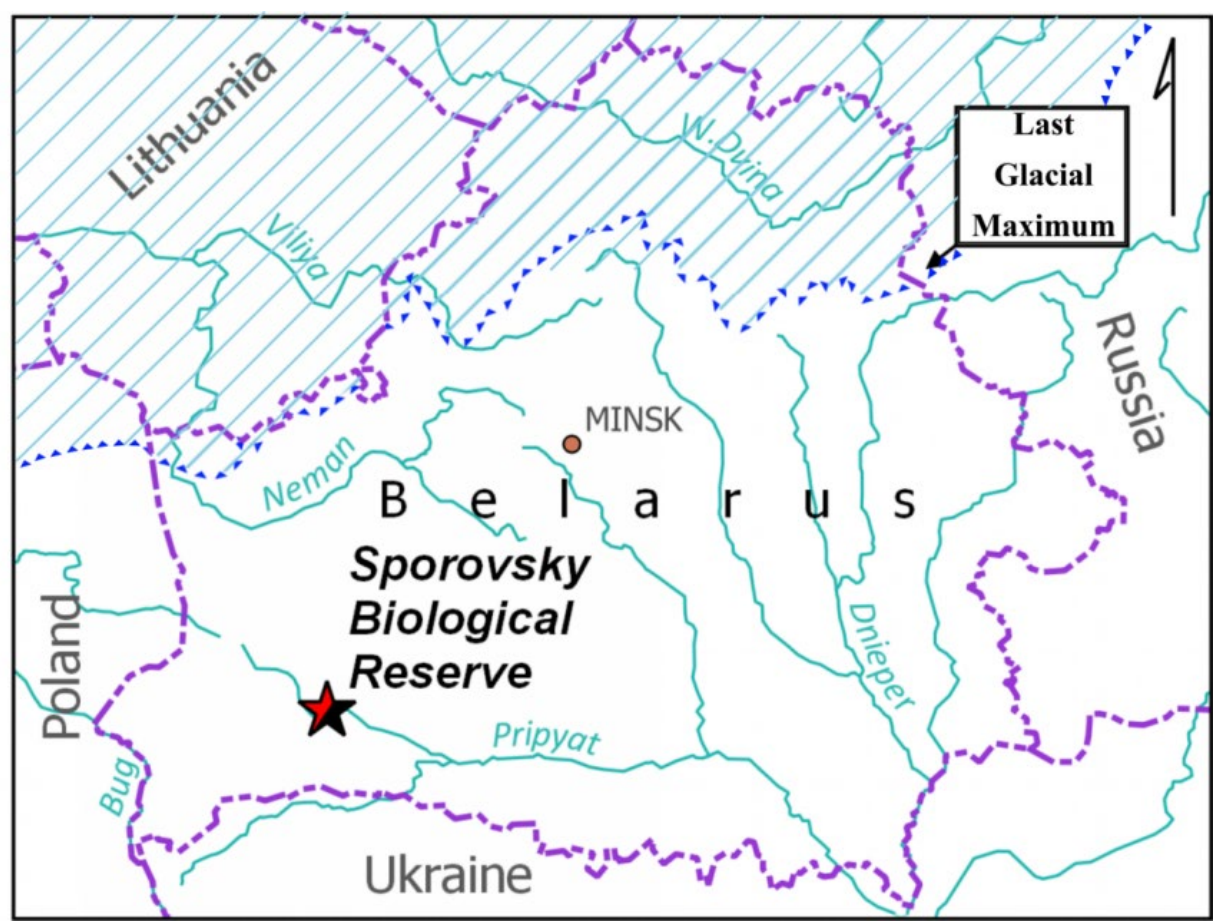

Figure 1. . Location of the Sporovsky Biological Reserve and the border of the LGM. 
Investigated site is characterized as a large peat-bog area with sandy hills in the basin of the Yaselda River (Pripyat tributary) and Lake Sporovskoe (Fig. 2 ). For the reconstruction of the palaeogeography of Sporovsky Reserve geological, geomorphological and geoarchaeological works were conducted on a peat-bog west of Lake Sporovskoe (profile "Sporovo II") and near the archaeological site "Kakoryca-4" located on a sandy hill (52²3'36.657"N 2517'34.355"E) (Fig. 3).

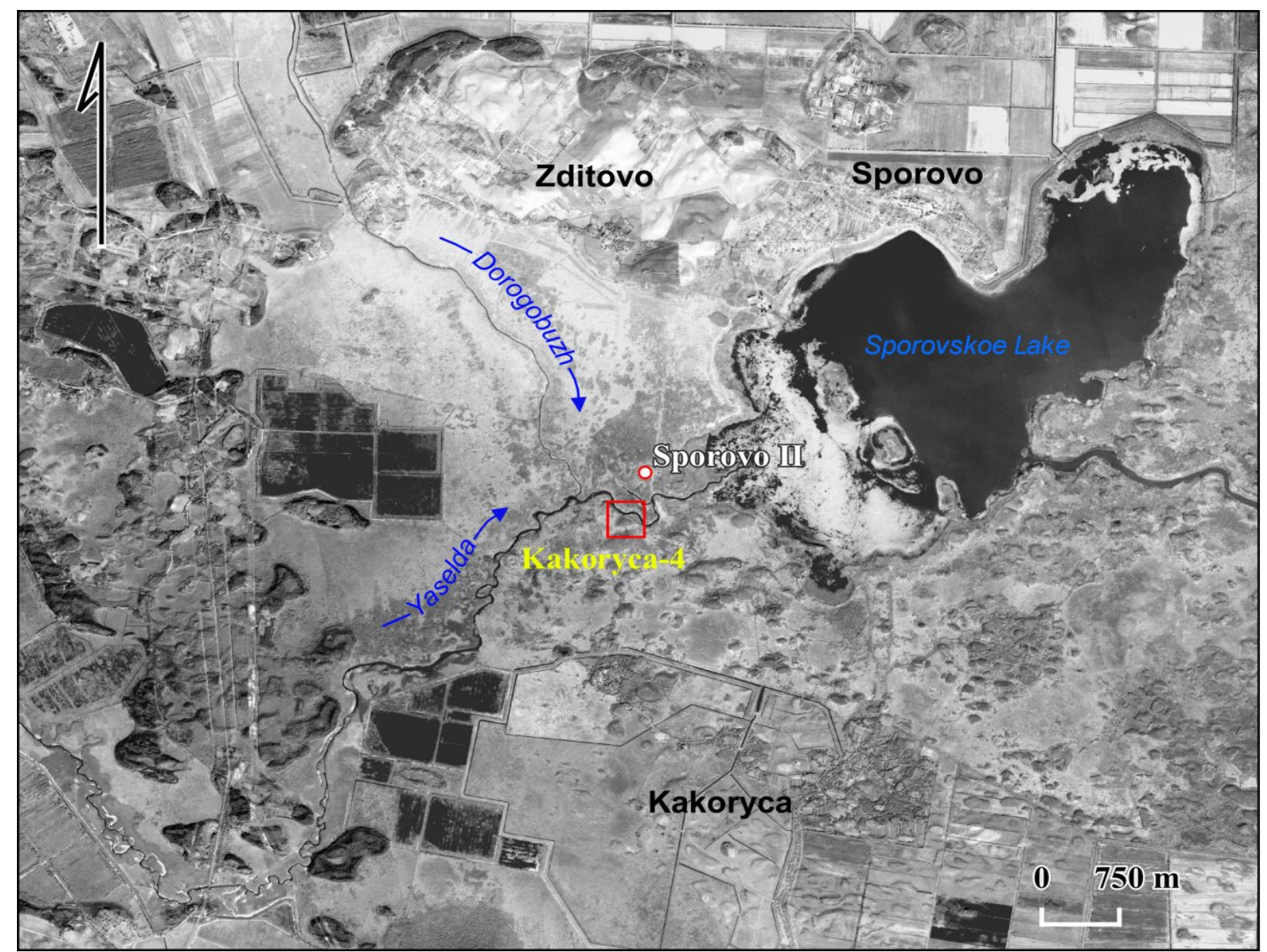

Figure 2. The territory of the Sporovsky Biological Reserve on

\section{METHODS}

The interdisciplinary research approach was applied. Field geological, geographical, cartographic works and archaeological excavations were carried out at the selected points. Exposed alluvial, lake sediments, peat-bog and sand (aeolian?) deposits were analyzed using palynological, sedimentological, radiocarbon analyzes (14C) and OSL dating. To create cartographic materials, a technique based on the analysis of remote sensing data was used. The multispectral and panchromatic optical-electronic sensing data from artificial Earth satellites, as well as manned and unmanned aerial photography materials, were processed and analyzed (Fig. 2,3, 4). 


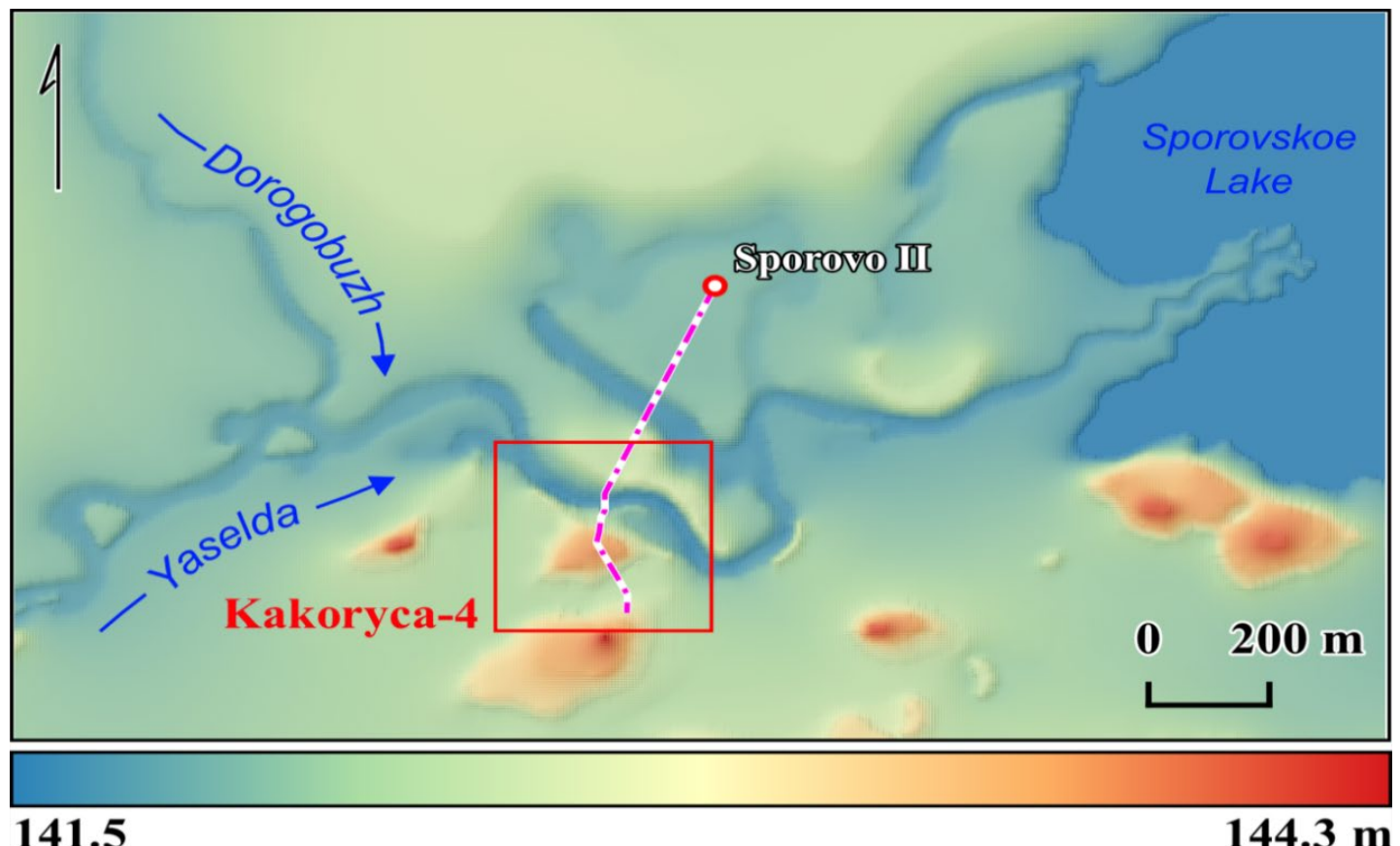

Figure 3. The investigated site and cross-section line based on geological boreholes, on a fragment of the digital elevation model (DEM) based on aerial photography materials.

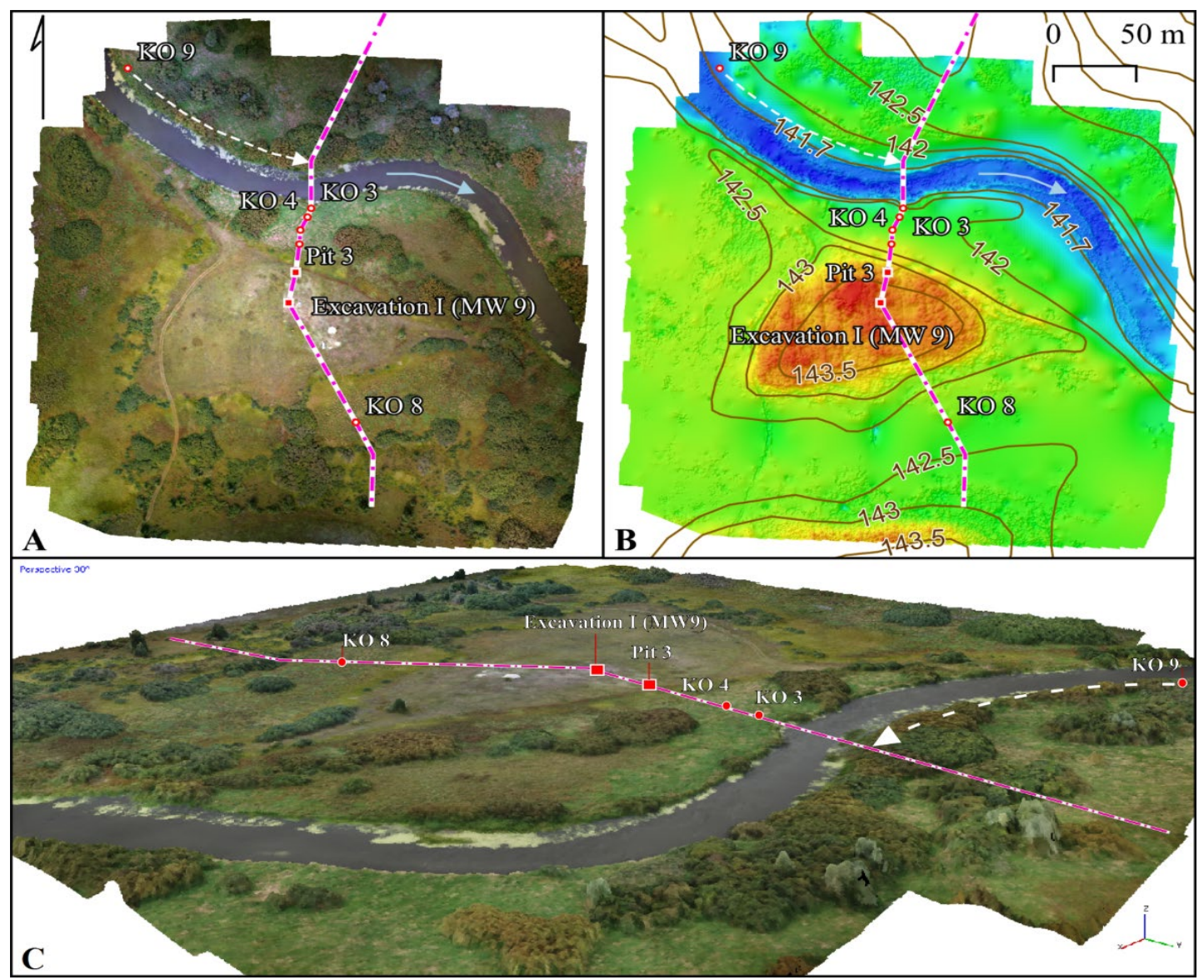

Figure 4. Archaeological site "Kakoryca-4" with cross-section line and boreholes on unmanned aerial photography materials: A-Orthophotomap; B-2d DEM; C-3d digital terrain model (DTM).

\section{RESULTS}

Based on the sedimentological analysis of deposits from profiles Sporovo II, KO3, KO4, KO8, KO9, MW9 and Pit 3, lithological diagrams and the section across the study area were drawn up (Fig. 5-
8). The cross-section and spatial reference of the boreholes were carried out using geodetic measurements (GNSS method) and DEMs based on aerial photography data. 


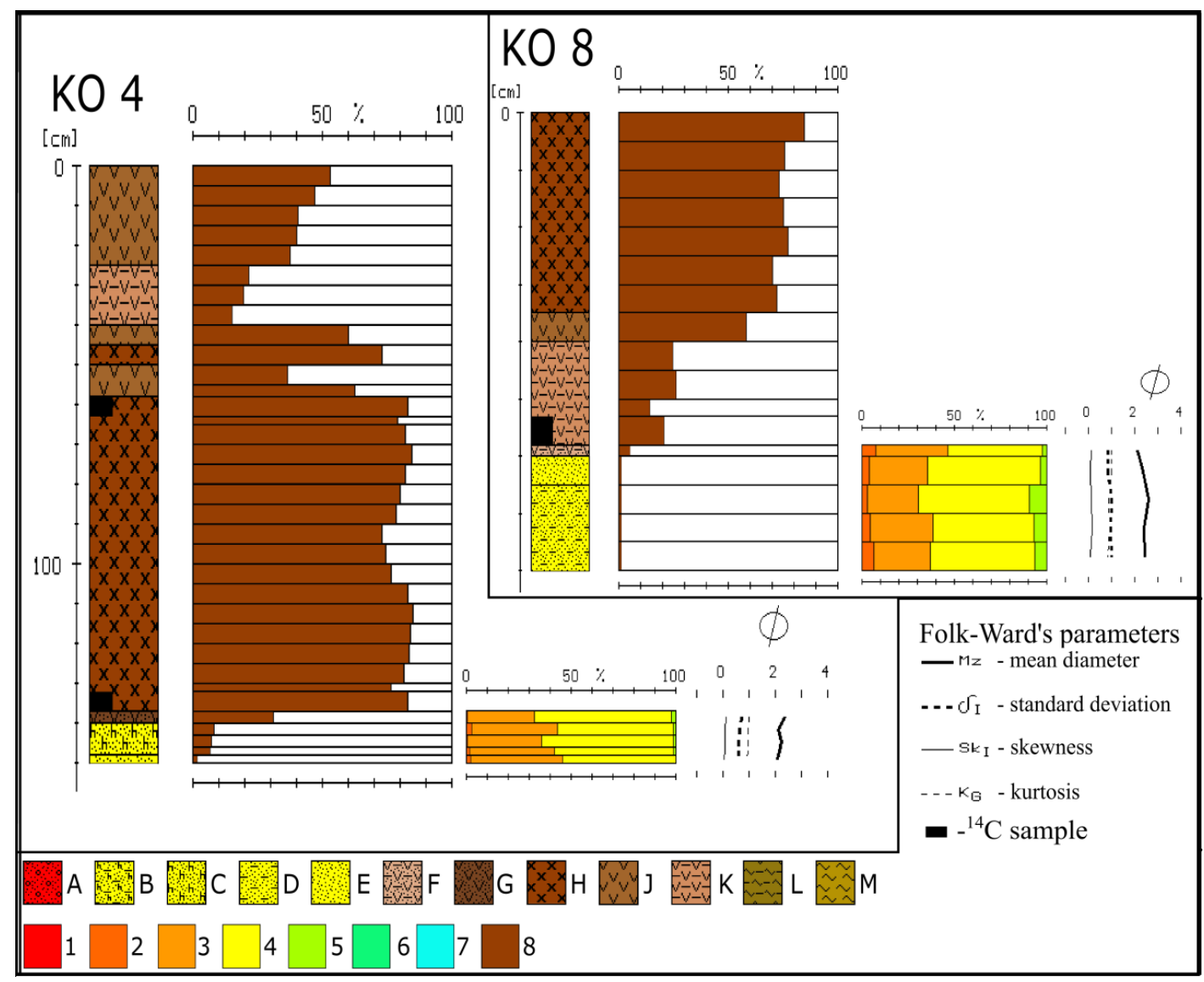

Figure 5. Lithological diagrams from profiles KO4 and KO8 (see location on Fig. 4)

Lithology: A-sands with single gravels, B-humous silty sands, C-humous fine-grained sands, D-silty sands, E-finegrained sands, F-sandy peaty silts, G-sandy peats, H-peats, J-silty peats, K-peaty silts, L-gyttja silts, M-gyttja; Fraction: 1-medium and fine gravels (under $-1 \phi)$, 2-coarse sands (-1 to $1 \phi), 3$-medium sands $(1-2 \phi)$, 4-fine-grained sands $(2-4 \phi), 5$-coarse and medium silt $(4-6 \phi), 6$-fine silts $(6-8 \phi)$, 7-clay (above $8 \phi), 8$-percentage of organic matter.

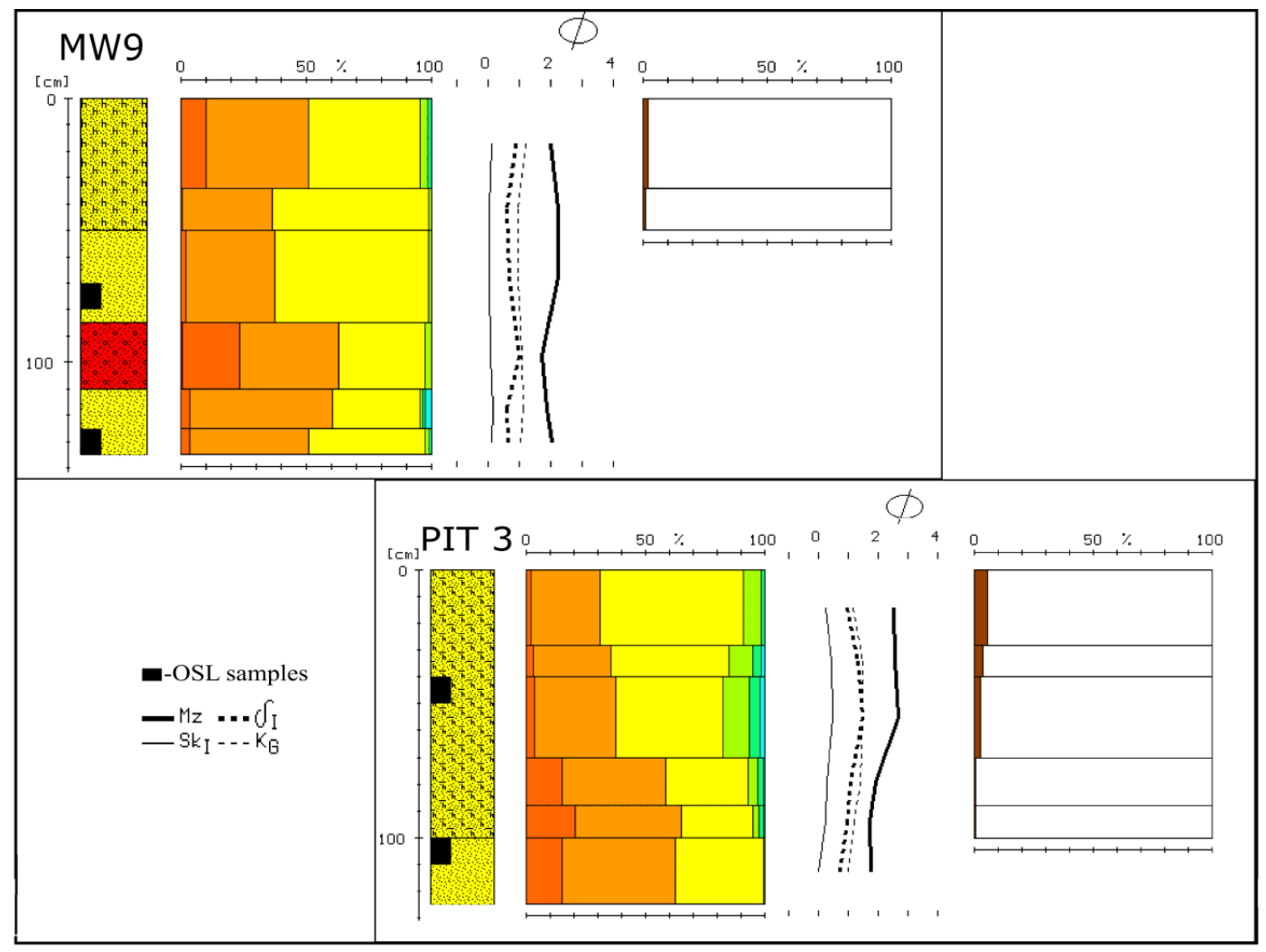

Figure 6. Lithological diagrams of profiles from sandy elevation MW9 and Pit 3 (see location on Fig. 4 and explanations on Fig. 5). 


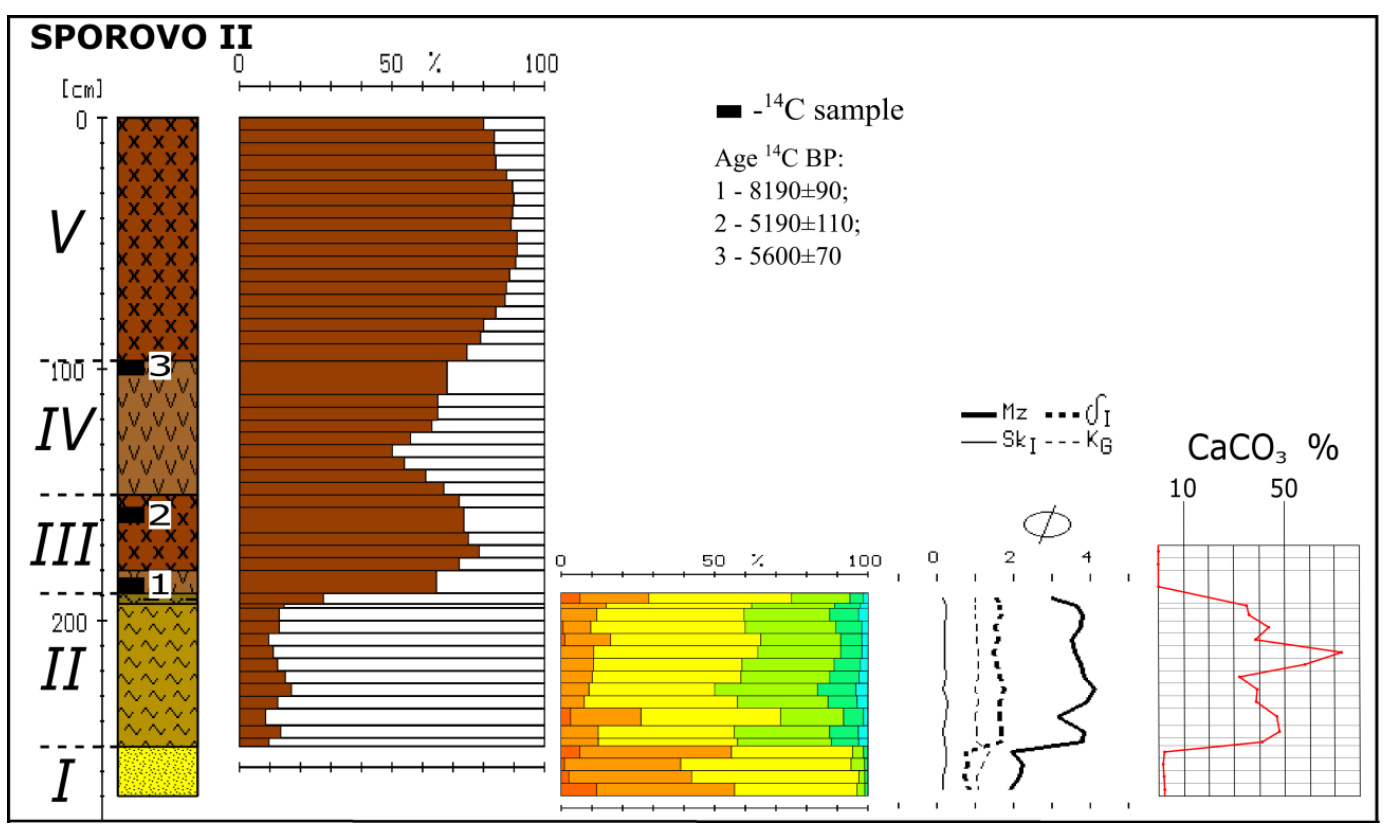

Figure 7. Lithological diagram of Sporovo II profile (see location on Fig. 4 and explanations on Fig. 5).

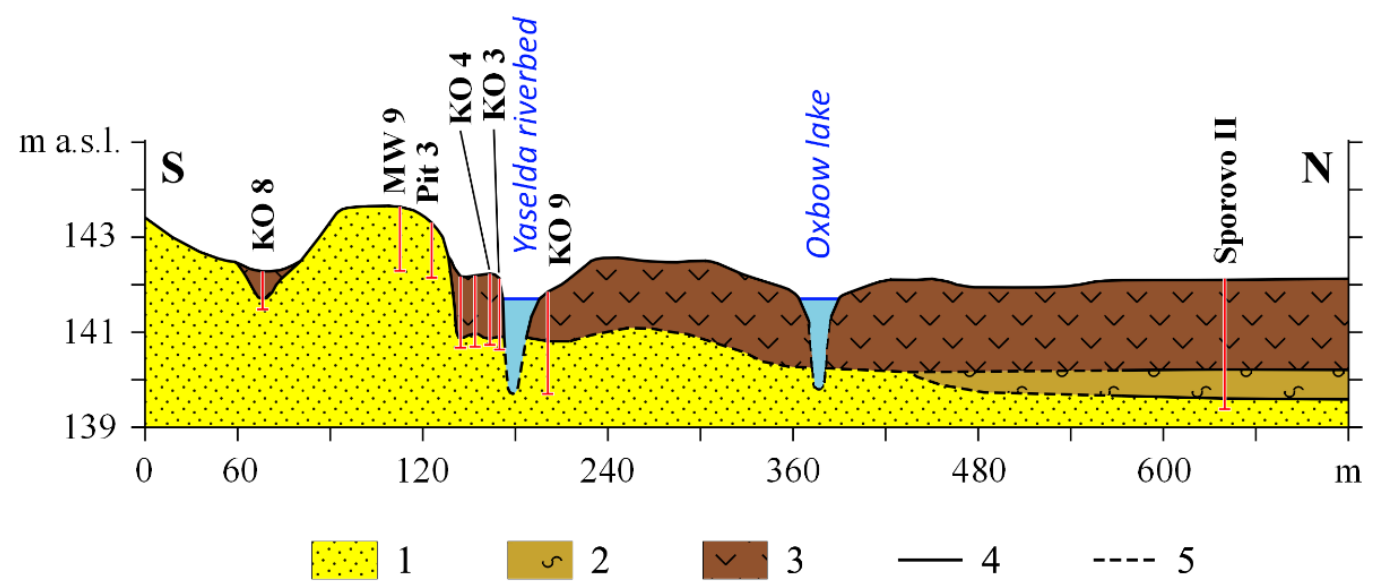

Figure 8. Geological cross-section of the study area from Sporovo II to KO8. 1-sands, 2-gyttja, 3-peats with different percentage of organic content; 4-established boundary line, 5-estimated boundary line

The analyzed sediments from Sporovo II profile were divided into five lithological members, reflecting a typical for Belarusian Polesie structure of sediments, when alluvial sands and lacustrine gyttja (I, II) are covered by peats with different percentage of organic content (III, IV, V) (Fig. 7). Palynological studies were conducted at profiles Sporovo II, KO4 and KO8. Local pollen assemblage zones (LPAZ) were identified based on cluster analysis (CONISS) and visual evaluation of pollen spectra. Five pollen zones, corresponding to the Holocene periods, were determined for the profile Sporovo II (Fig. 9), considered as a reference. The chronology of paleogeographic events was restored based on radiocarbon dates obtained for the Sporovo II, $\mathrm{KO} 4$, and KO8 profiles, as well as the correlation of local pollen zones with regional pollen zones (RPAZ) of the Holocene for Belarus. The radiocarbon dating of peat samples from the Sporovo II core is presented in Table 1.

Table 1. Radiocarbon measurements from the Sporovo II profile.

\begin{tabular}{|c|c|c|c|c|c|c|}
\hline \multirow{2}{*}{ № } & \multirow{2}{*}{$\begin{array}{c}\text { Depth } \\
(\mathrm{cm})\end{array}$} & $\begin{array}{c}\text { Dated } \\
\text { material }\end{array}$ & $\begin{array}{c}\text { Reference } \\
\text { laboratory }\end{array}$ & ${ }^{14} \mathrm{C}$ yr BP & \multicolumn{2}{|c|}{\begin{tabular}{c} 
Calibrated time (cal. yr BC) \\
\cline { 4 - 6 }
\end{tabular}} \\
\hline 1 & $97-103$ & silty peats & MKL-4786 & $5600 \pm 70$ & 4598 & 4331 \\
\hline 2 & $155-161$ & peats & MKL-4785 & $5190 \pm 110$ & 4321 & 3715 \\
\hline 3 & $183-189$ & silty peats & MKL-4784 & $8190 \pm 90$ & 7494 & 6866 \\
\hline
\end{tabular}




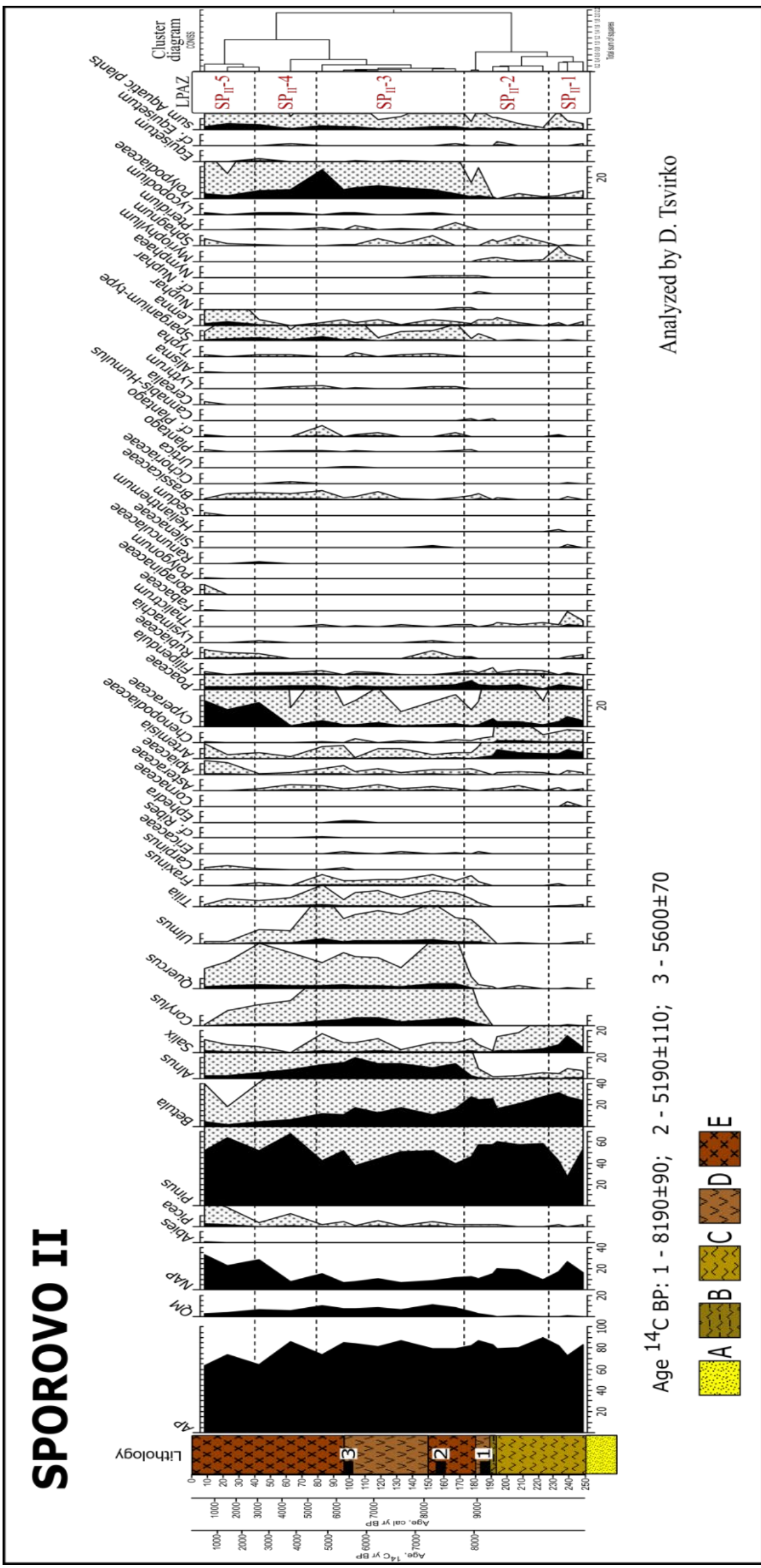

Figure 9. Percentage pollen diagram from Sporovo II with a time scale showing the estimated age of the deposits A-fine-grained sands, B-gyttja silts, C-gyttja, D-silty peats, E-peats. 
The cultural layer of the archaeological site "Kakoryca-4" was saturated with a large number of finds: flint and stone artefacts, pottery, and bone remains. Bone material are relatively well preserved. Most of the archaeological finds date back to the Neolithic and Bronze Age (V-II millennium BC). Some flint products were characterized by signs of the Late Mesolithic Janisławice culture (VI-V millennium BC).
Ceramic fragments of the Iron Age and Middle Ages are also distinguished. The Neolithic and Bronze Age periods are represented by the finds of the following cultures: Pripyat-Neman and Neman Neolithic cultures (V-III millennium BC); the Corded Ware culture circle and Epi-Corded Ware culture horizon (middle of the IIIrd - beginning of IInd millennium BC); Trzciniec Culturel Circle (II millennium BC) (Fig. 10).

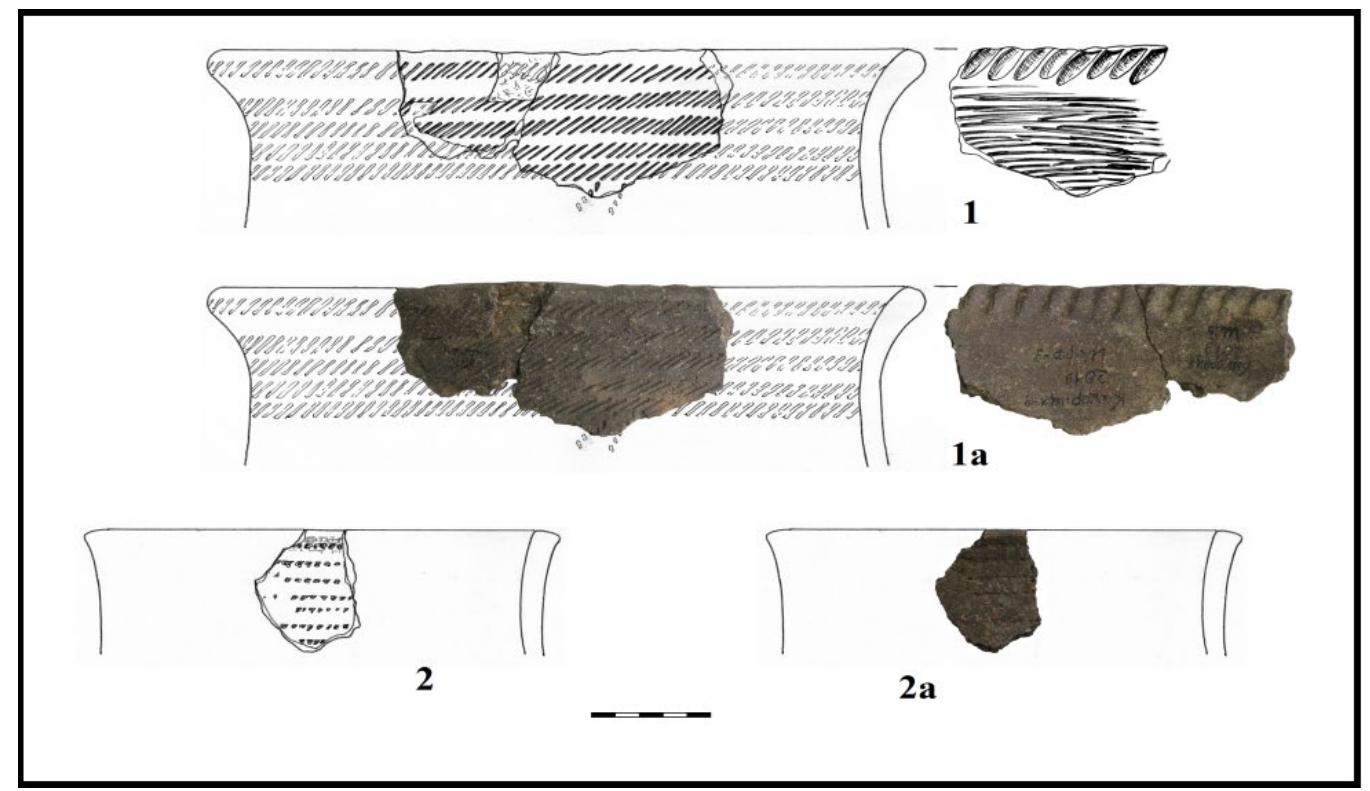

Figure 10. Pottery of the Corded Ware culture circle (1-1a) and Trzciniec Culturel Circle (2-2a), "Kakoryca-4" site (by Mikola Kryvaltsevich).

\section{DISCUSSION AND PRELIMINARY CONCLUSIONS}

Obtained data and literary sources [3], [4] show the development of the territory of the Sporovsky Reserve during the Holocene. According to palynological and radiocarbon analyses, it was found that in the Early Holocene on the territory of Sporovsky Reserve there was a large lake in which carbonate gyttja deposited [5] (Fig. 7). The beginning of this accumulation was palynolgical dated at Preboreal (Fig. 9 - SPII-1). The same sedimentation type occurred in Belarusian lakes (Polesie and Poozerie regions) in Younger Dryas and Preboreal [6]. The accumulation of calcareous gyttja in Boreal period is also common in these regions. Around the same time we could observe increase in the tendency of lake level change in these regions [6]. In Sporovo, alike in other reservoirs in this region, the formation of carbonate sediments reflects an important stage of lake development, connected with a considerable general warming of the climate at the beginning of the Holocene [6]. At the time of intensive sedimentation of calcareous deposits the lakes were oligotrophic-mesotrophic and the sediments were poor in organic matter [7] (Fig. 7 - II member). In the end of Boreal and beginning of Atlantic (8190 \pm 90 BP, 7494-6866 cal. yr BC) we can observe peat accumulation on calcareous deposits in profile Sporovo II (Fig. 9). This time was characterized by the accumulation of peats (Early Atlantic) and after that silty peats until $5600 \pm 70 \mathrm{BP}$ (4598-4331 cal. yr BC) - end of the Atlantic, which may be connected with warm and dry climate in the Subboreal period [4].

This can be reflected in the water level in Lake Sporovskoe, just like it did in Lake Bobrovichskoe [6] in this region at the same time. It should be noted that the result of radiocarbon measurement of a peat sample from Sporovo II at a depth of 155-161 cm (Table $1-5190 \pm 110$ BP) was most likely distorted due to contamination of the sample with younger deposits.

With a high probability the territory of the archaeological site "Kakoryca-4" was used in agricultural activities. This is evidenced by field observations in adjacent areas, as well as the striped image structure of the hill surface on the DEM, based on unmanned aerial photography materials (Fig. 4B). 


\section{REFERENCES}

[1] Bronk Ramsey C. Methods for Summarizing Radiocarbon Datasets. Radiocarbon, 59 (2), pp, 1809-1833, 2017.

[2] Reimer, P., Bard, E., Bayliss, A., Beck, J., Blackwell, P., Ramsey, C., . . Van der Plicht, J.. IntCal13 and Marine13 Radiocarbon Age Calibration Curves 0-50,000 Years cal BP. Radiocarbon, 55(4), 2013, 1869-1887. doi:10.2458/azu_js_rc.55.16947

[3] Zernitskaya V. Palynology of bottom sediments of Lake Sporovskoe, Geology and hydrogeology of the Cenozoic of Belarus, Belarus, pp 56-60, 1985 [in Russian].

[4] Krutous E. Paleogeography of the Anthropogen of Belarusian Polesie, Belarus, 143 pp, 1990 [in Russian].

[5] Tsvirko D., Kryvaltsevich M., Tkachou A., Trifonov Y., Kalicki T., Frączek M. \& Kusztal P. Late Glacial and Holocene environmental changes on the territory of Sporovsky Reserve (Belarusian Polesie), 25th Quaternary Conference Kvarter, Czech Republic, 2019, p 63.

[6] Novik A., Punning J.-M. \& Zernitskaya V. The development of Belarusian lakes during the Late Glacial and Holocene, Estonian Journal of Earth Sciences, pp 63-79, 2010.

[7] Zhukhovitskaya A, Vlasov B, Kurzo B \& Kuznetsov V. Holocene lake sediments of Belarus: geochemical and biological aspects, Belarus, 276 pp, 1998 [in Russian]. 